20/20 Hindsight: A 25-year programme at the Anna Freud Centre of efficacy and effectiveness research on child psychoanalytic psychotherapy

Mary Target $\mathrm{PhD}^{1 *}$

${ }^{1}$ Research Department of Clinical, Educational and Health Psychology, University College London, London, UK

* Correspondence concerning this article should be addressed to Professor Mary Target, Research Department of Clinical, Educational and Health Psychology, University College London, 1-19 Torrington Place, London WC1E 7HB, UK. E-mail: m.target@ucl.ac.uk 


\title{
20/20 Hindsight: A 25-year programme at the Anna Freud Centre of efficacy and effectiveness research on child psychoanalytic psychotherapy
}

\author{
Abstract \\ This paper describes the evolution of methods of enquiry - through 25 years of work, \\ with Professor Peter Fonagy and many other colleagues - of research and theorizing \\ about child and adolescent therapy outcomes. The work has been based within a \\ psychoanalytic context, but with an increasing emphasis on discovering therapeutic \\ elements within diverse treatments. I will attempt to draw helpful lessons for others \\ from the ups and downs of developing (a) retrospective, follow-up, and prospective \\ outcome studies, and (b) measures of child and family functioning. Issues of \\ manualizing and measuring treatment process will be discussed, as will the fruitfulness \\ of mixed-method (quantitative and qualitative) process and outcome research with \\ young people and families. While my dilemmas, experiences, and findings are given as \\ examples, concluding observations will be more widely applicable to discovery and \\ interpretation in psychotherapy research.
}

Keywords: child psychotherapy, long-term psychotherapy, outcome research, psychoanalytic/psychodynamic therapy, qualitative research methods 


\section{Introduction}

This article responds to the editors' request for an overview of the long-term research programme within our group, led by Professor Peter Fonagy and myself, on the efficacy and effectiveness of psychoanalytic psychotherapy for children and young people. This form of therapy is not mainly symptom-focused, but aims to help the young person presenting with problems such as anxiety, depression, psychosomatic, family or relationship difficulties to uncover underlying issues, allowing pervasive and long-term change in problematic aspects of personality and reduction in secondary symptoms. The work focuses on the so-called internal world including unconscious processes and motivations, such as disabling conflicts about competition, the body, or learning, and defensive compromise 'solutions' to these such as phobic avoidance or depressive withdrawal, self-harm, hypochondriasis, aggression or persistent rule-breaking. There may be developmental deviations such as delays or attachment abnormalities, which can be linked to relational trauma. The therapeutic work is usually extensive: classical psychoanalysis would involve 4-5 50-minute sessions per week for some years, and 'non-intensive' psychotherapy 1-3 sessions per week for at least a year. Parents generally also have sessions aimed at better understanding of the young person's difficulties, and consistency in therapeutic approach (e.g. helping foster-carers to imagine why a neglected child has begun to soil in his room, and break or steal objects of sentimental value from them, when told about a family holiday). There is commonly a focus on the relationship with the therapist or analyst, assumed to involve a 'transference' of expectations and reactions from earlier and current family relationships, which allows therapist and patient to recognise these expectations and reactions, and consider where they were coming from. This enables intense unconscious conflicts and developmental pressures to be understood and processed, with less need to express them in symptoms, regression from developmental achievements and so on. 
Below, I describe a programme of work which has parallel strands, including theory, multiple research designs, measure development, collecting different types of outcome data, new treatment development, and active engagement with policy, all of which were developed simultaneously to create enough momentum for progress to occur in spite of obstacles. These obstacles were not only the universal ones for researchers in our field: obtaining funding; satisfying research ethics committees; recruiting sufficient participants; and simply starting from a robust design and analytic strategy (never simple, of course). The obstacles were not even just these plus the extra roadblocks for child mental health: research ethics requirements on acceptable interventions, and on informed consent from children, and parents; the fact that children are developing within a context of (usually) family and school, which may themselves be contributing to the disturbance and unable to give reliable assessments of the child's difficulties.

\section{So, why are there particular challenges to doing research in this field?}

Every field of research has its special challenges. In this context, there are a number of linked issues: psychoanalytic psychotherapy is a relatively long and intensive intervention, which has classically been open-ended and unstructured, with supervision relying on therapists' notes rather than recordings; the aim of the therapy is to modify unconscious processes such as defences against anxiety, and unconscious representations, especially internal object relationships (e.g., perceiving close dependent relationships as dangerous because of expected attacks, envy, treating the child as part of the parent, etc.), rather than to reduce specific - and measurable - behaviours or symptoms such as school refusal, self-harm, soiling, and eating disorders. So, the reader can immediately anticipate issues of:

- outcome evaluation which captures the results aimed at, 
- finding a good comparison condition for long-term, intensive therapy (somehow controlling for wider developmental and contextual change over a year or two of treatment)

- manualization of technique, with recording of sessions, allowing assessment of competence and adherence.

A further, substantial obstacle facing formal research into the outcomes of psychoanalytic psychotherapy was (although this gradually changed, beyond recognition) the indifference at best, and often antagonism in principle, of practitioners to the idea of cooperating with empirical process / outcome research. Some reasons for this antagonism follow from obstacles above:

- an assumption that unconscious processes and changes could not be measured by standardized instruments, and that usual symptom or diagnostic measures would not be sensitive to the level at which change would be occurring

- similarly, that technique is rooted in concepts and principles that do not produce standard technique and could not be manualized, or judged as adequate or inadequate by any process measures

- a belief that material within sessions is too confidential and delicate to allow session recordings (there may also sometimes have been an anxiety that these could embarrass the therapist), and that the treatment would also be disrupted by external intrusions such as outcome questionnaires or interviews.

The position of the psychoanalytic researcher in the 1980s, when this programme began, was sobering for the many reasons outlined above. Furthermore, there was the growth 
of shorter-term, symptom-focused models, especially cognitive-behaviour therapy (CBT) that generally made sense to patients, colleagues, and funders. This was in many ways to be welcomed, providing fast and often effective help to distressed children and families. However, it posed real challenges for launching research on psychoanalytic child psychotherapy, whose theory and clinical experience required an intensive, long-term approach focused below and beyond the level of symptoms, on conflicts, developmental restrictions (including dysfunctional attachments) outside awareness, potentially fundamental but much harder to measure and link to treatment process.

I would say that, at that time, many psychoanalytic psychotherapists unintentionally made matters worse by tending to regard their approach as needing no external evidence and seeing all empirical evaluations as intrusive. Funders and managers of services were inclined to respond by investing in more transparent, modern approaches with face validity, at least for children with circumscribed problems. However, children with more complex, pervasive, and entrenched difficulties, or those who had suffered attachment trauma, often continued to be referred to psychodynamic psychotherapists because there were no alternatives with an evidence base (or short-term, symptom-focused approaches had not helped the child), and the range of professionals working with these children believed that this form of therapy offered the necessary depth, consistency, and capacity to understand and withstand the disturbing behaviour of many such children.

\section{“But hang on, couldn't we just use the adult research...?"}

That half-serious suggestion, made by some clinicians and researchers aware of some evidence for the efficacy of adult psychoanalytic psychotherapy, would have saved a lot of hand-wringing. But many childhood disorders do not occur in adulthood, or take a very different form; hence, treatments may not have been evaluated or the findings of adult studies 
could not be generalized to children. In addition, the developmental contexts are quite different (referred children are looked after by adults, often with intergenerational social and psychological problems, and most go to school). These differences create complications but also great opportunities to deliver interventions supported by those contexts (e.g., family therapy, parent training, school-based treatment). It is also important to recognize that some common adult treatments (e.g., medications, cognitive therapy) work differently for children, can be used only above a certain developmental level, or may carry different risks.

\section{Was there even a prima facie case for effectiveness here?}

Despite the specific hurdles for research on this topic, our group was hugely fortunate in that the Anna Freud Centre (formerly the Hampstead Child Therapy Course and Clinic) had a tradition, since its founding after World War II, of highly systematic and extensive routine documentation of diagnostic and clinical material, and of large-scale developmental observation (e.g., of the consequences of separation by war, of chronic physical disabilities, and of adoption following parental abuse or mental illness). It also had a solid record of welldescribed and fully-published conceptual research (for example the Hampstead Index Project, Sandler, 1962). The staff and trainees at the Centre were therefore well-used to reliable and detailed recording, and to close monitoring of treatment. A small number of previous, innovative empirical research studies of outcomes had also been conducted:

(1) Heinicke \& Ramsey-Klee (1986), studying the impact of psychoanalytic psychotherapy on learning disability, established that a higher frequency of therapy (four vs. one sessions per week) increased effectiveness.

(2) Moran, Fonagy, Kurtz, Bolton, and Brook (1991), kicking off the Anna Freud Centre programme of research to be described below, showed in a small but ingeniously designed process-outcome study that four times weekly psychoanalytic psychotherapy 
substantially improved short- and long-term physical measures of control ${ }^{1}$ in intractable cases of brittle diabetes in childhood.

Since the 1980 s, a few other research studies with increasingly strong designs have been done (notably studies from the Tavistock Clinic by Judith Trowell and colleagues; e.g., Trowell et al., 2002, 2007), but even when we started, there were grounds for cautious optimism and investment.

\section{Our research programme, or: be careful what you wish for}

Establishing a credible and effective evidence base for child psychoanalytic psychotherapy required preparatory work on a much broader set of fronts than simply designing and raising funding for outcome studies. The programme has encompassed six streams:

(1) Earning trust within the clinical profession. We started with minimally intrusive methodologies - retrospective and follow-up studies - and engaged extensively with the extra ethical and clinical dilemmas involved in researching this form of treatment.

(2) Designing and validating new outcome measures, piloting a Randomised Controlled Trial (RCT) protocol and making the case for funding. We devised measures of childhood adaptation and normal and pathological emotional and behavioural development, including child-parent attachment and internal object relationships.

(3) Developing a theoretical model of mental development. We tried to understand and describe how treatment technique and outcomes related to psychoanalytic theory, developmental psychology and perhaps other treatment modalities.

\footnotetext{
${ }^{1} \mathrm{HbA} 1 \mathrm{C}$ levels and predicted adult height based on current height and bone age.
} 
(4) Developing new treatment models. These needed to be coherently based on the theory and clinical experience across treatment models, which allows testing of the theory and potentially briefer and more powerful intervention strategies.

(5) Establishing credibility within the field of child mental health outcomes. This was undertaken through: leading systematic reviews of outcome studies across all modalities (treatment models such as CBT, and methods such as individual vs family, etc); and serving in senior roles in public sector evidence-based practice guideline development groups (GDGs) - starting with the Child Depression GDG for the UK's National Institute for Health and Care Excellence (NICE) and, subsequently, other GDGs concerned with the mental health of children

(6) Designing and conducting a major randomized controlled trial (RCT) using quantitative and qualitative methodologies, to address the shorter- and longer-term results of psychoanalytic psychotherapy in respectful comparison with leading alternative treatments.

Readers will understand that such multi-faceted work requires not only 25 years but also a very talented team - in which respect our group has been tremendously fortunate. Some major members of the teams who contributed especially creatively will be mentioned below as studies are outlined.

The remainder of the article will summarise work across the six streams above, with some headline results, and then reach some conclusions which I hope may inform the work of today's early-career psychotherapy researchers.

\section{(1) Earning trust within the clinical profession}

This issue was a major factor in initial opposition to preparing to evaluate the efficacy of this modality. Child psychotherapists were protective towards their model and the privacy of their 
work and patients, and very sceptical that outcome research could capture what was achieved within it, at any rate without destroying it in the process. Dealing with powerful unconscious forces underlying psychopathology was felt to need a level of seclusion, and to endow a degree of superiority, because the therapy was focused on addressing the hidden mainsprings of disorder rather than on fixing problems at the surface. This assumption of reaching a deeper level - getting to the heart of children's problems, but in a way that could not easily be shared - perhaps contributed to a scepticism towards this approach on the part of other practitioners, funders, and researchers. One might, from a psychoanalytic angle, go so far as to say that psychoanalytic clinicians used to react to pressure to allow outcome research as though it were an envious attack that would violate the purity of their fragile creative processes, whereas other clinicians and researchers became impatient with the claim to special status and immunity from the penetrating enquiry expected of other publicly provided treatments.

I think it was helpful that our programme began in an unobtrusive way, with a retrospective study of predictors of outcome among the 800 or so completed cases (763 of which met inclusion criterion of sufficient documentation) treated at the Anna Freud Centre in the previous 40 years.

A retrospective study of 763 cases over 40 years: Identifying predictors of outcome (Fonagy \& Target, 1994, 1996; Target \& Fonagy, 1994a, 1994b)

In this chart review study, we systematically codified information, in collaboration with Yale Child Study Center colleagues Professors Alan Kazdin, Donald Cohen, and Linda Mayes, aiming at statistically disentangling predictors of objective outcomes coded retrospectively from the excellent case records: diagnosis, Children's Global Assessment Scale (CGAS; Shaffer et al., 1983) scores, and remaining symptoms. Scores on the CGAS, a global "thermometer scale" of adaptation and symptom level, had a reputation in the literature of 
being excessively impressionistic; we therefore created a manualized coding system, the Hampstead Child Adaptation Measure (HCAM: Target, Fonagy, Schneider, Ensink, \& Janes, 2000), in which 14 100-point dimensions or domains were coded with anchor-points tied to age bands, followed by deriving global scores and indices of unevenness of functioning across domains (this is one of the parts of our programme that I would not recommend: do not try this at home, or anywhere else ... developing and validating the scoring system requires levels of obsessionality and masochism unusual even among researchers!). In this retrospective study, the HCAM was used to summarise functioning across domains (e.g. peer relationships, care of the body and safety, capacity to learn, psychosexual development), before and after treatment, on the basis of the very detailed case records, therapy process notes and information from parents and teachers.

Some of the findings emerging from the retrospective study were that:

- Younger children made the greatest gains (in adaptation and symptomatology) during treatment (Target \& Fonagy, 1994b)

- Children with anxiety disorders did better by the end of treatment than those without, even with comorbid or primary disruptive disorders (Target \& Fonagy, 1994a)

- Intensive therapy (four or five sessions per week) showed substantially better outcomes than less frequent treatment for children with more complex symptomatology (more than one disorder, e.g., both emotional and specific learning disorders, established in more than one domain of the child's functioning), while these children commonly did not show clinically significant improvement with one or two sessions per week of therapy. Notably, this result had not been predicted; although very complex cases are most often referred for psychoanalytic psychotherapy in public clinics, seeming to justify the cost and often because there is no obvious 
alternative, the traditional understanding had been that intensive psychoanalytic treatment (4-5 sessions weekly) was most suited to neurotic children who were otherwise functioning adequately. Our finding was that those children with less complex psychopathology benefitted just as much from less frequent sessions, in terms of diagnosis and adaptation (we could not retrospectively assess changes in the "internal world" of the child; this was to come in later work), while children with more pervasive pathology tended not to do well with less frequent sessions (Fonagy \& Target, 1996)

- Treatment length and intensity independently predicted better outcome (Fonagy \& Target, 1996)

- Predictors of outcome varied in further ways with age and diagnostic features, for example the added benefit of more frequent sessions was significantly greater for younger children (under 6) compared to school-aged children or adolescents, and children with pervasive developmental disorders tended not to show much improvement. Most of the latter were treated in the early years of the Centre, when classical technique was being used, and children seen equally intensively later with a developmental help technique showed greater gains, in fact sometimes very large increases in adaptive functioning (Fonagy \& Target, 1996).

Any able student in our field could immediately list issues with the retrospective study, which constitutes fairly weak evidence: the population treated was not representative, there was no external comparison group, and, although records were highly systematic, outcome assessment was retrospective. What was gained by the work, in addition to getting clinicians used to their work being externally evaluated, was the generation of hypotheses and preliminary trends in outcome, where RCT methodology was particularly tricky (see above) and calibration of developmental courses of disorder did not exist. In addition, we needed the 
time to develop more relevant measures of change, and to manualize child psychoanalysis. An RCT for long-term treatment was not likely to be fundable without such groundwork and preliminary evidence.

A long-term follow-up of cases from the retrospective study (Schachter \& Target, 2009; Target \& Fonagy, 2003)

One of the next questions our group engaged with was the outcome in adults of childhood disorders that were treated in different ways or had not received treatment. We had shown that children functioned better than expected after a long and costly therapy, but without an untreated group it was important to show that these improvements were attributable to the therapy. As well as a prospective RCT, a very long-term follow-up study could test the possibility that the gains were maintained long-term, suggesting greater resilience, which would help to justify the large investment of children's and families' time in analysis. There were alternative hypotheses here: Anna Freud herself had conservatively suggested that the aim of analysis was to restore the child to the path of normal development, especially in cases where there had been developmental distortion (Freud, 1976), and that analysis should not claim to prevent later problems, for example, in the adolescence of a child whose early anxiety disorder had been resolved. Our group had, however, been working on ideas of resilience developed through secure attachment relationships and the capacity for mentalizing (see below), and we ventured to predict that early therapy might increase these measurable aspects of functioning, which had been separately shown to be associated with greater resilience to stress and better outcomes in terms of relationships and emotional wellbeing (Fonagy, Steele, Steele, Higgitt, \& Target, 1994; Fonagy \& Target, 1997a, 1998). 
We gave thought to what might be the best ways to control for family and cultural factors, and for degree of disturbance before treatment ${ }^{2}$. We decided to try to find a group of people who had been treated at the Anna Freud Centre as children, their closest untreated sibling, raised in the same family around the same time but not referred, and a further group of untreated, referred children matched on symptomatology in childhood and other variables found in the previous study to be related to outcome. We were interested to find out whether the differences in immediate outcome observed in our chart review study would persist into adult adjustment and functioning: would social adversity and psychiatric difficulties be especially likely to persist or recur where developmental delays and distortions were not addressed through intensive psychotherapy?

We used three types of measures:

(1) In-depth interview-based objective measures of life events, transitions, and plans, current personality functioning, and memories of childhood experiences of care and maltreatments, as well as retrospective psychiatric and personality disorder diagnosis. Despite some subjectivity, these instruments have high levels of reliability, and the track record of the research groups that had used these instruments (e.g., Bifulco, Brown, Moran, Ball \& Campbell, 1998; Hill, Fudge, Harrington, Pickles, \& Rutter, 1995) showed that they could connect lifespan environmental influences and psychopathology.

(2) Self-report measures of symptomatology (SCL-90), physical health (SF-36), IQ, personality (SCID-II), etc.

\footnotetext{
${ }^{2}$ A consultation with Professor Sir Michael Rutter informed the design. This project was managed by
} Dr Abigail Schachter. 
(3) Psychodynamic measures of attachment and internal representations of "object relationships" (e.g., George, Kaplan, \& Main, 1985; Westen, Muderrisoglu, Fowler, Shedler, \& Koren, 1997).

We did get some interesting results, mainly that adults treated at the Centre in childhood fared far better in their later years than did those who were assessed as similarly troubled but, for largely pragmatic reasons (usually travel and conflicting family needs), were unable to accept the offer of psychotherapy (for an overview of the study and results, see Schachter \& Target, 2009). Those children who had received treatment but did not show improvement at the time (as independently recorded in the earlier study; these were sometimes children whose parents did not continue to bring the child after a short period) had adult outcomes comparable to that of the untreated referred group; however, those who had improved during their early treatment had outcomes as strong as those of their siblings who had not been seen as disturbed at the time. The treated siblings were in fact doing better in terms of mentalizing, frequency of negative life events, capacity to cope effectively with stress, and quality of love relationships. Our qualitative analysis of the rich interview material with participants covering a range of outcomes allowed us to explore the meanings of these pathways, to the participants themselves (Midgley and Target, 2005; Midgley, Target, \& Smith, 2006).

Both those treated with good childhood outcome and non-referred siblings were highly likely to have a secure attachment classification. Those unsuccessfully treated appeared to be predominantly "preoccupied/entangled" as adults, whereas those untreated appeared to be predominantly "dismissing". Interestingly, while treated siblings were mostly coded as "earned secure", their non-referred siblings tended not to recall the adverse childhood circumstances that had been documented in detail in the treated child's family records. In the light of the contemporaneous accounts, the untreated siblings who gave a 
relatively straightforward account of an easy childhood were idealizing and much less realistic than their siblings who had been in therapy. Even major events recorded contemporaneously (e.g., divorce of the parents during the child's adolescence, a prolonged hospitalization of the mother with difficult convalescence and separations) might be described as important by the treated sibling but not mentioned by their brother or sister. It was a fascinating experience, as a blind coder of the Adult Attachment Interviews (AAIs), to find that siblings close in age could rarely be matched as having come from the same family; sometimes when the blinding was broken after coding had ended, I was certain that the ID numbers must have got mixed up as these individuals could not have been describing a shared childhood. The heavily selective recall of childhood, retaining a coherent and plausible narrative, seems to be a form of idealization that cannot be picked up in AAI coding; in most studies we do not have a way of knowing whether substantial difficulties have been edited out to sustain a rose-tinted picture. It may be that the somewhat greater resilience to later stress of the treated siblings is connected with their capacity to make sense of difficulties on a psychological level (i.e., to mentalize), rather than having to "delete" inconvenient memories, feelings, and thoughts (Target \& Fonagy, 2003).

The AAI extract below, from a woman who had been in therapy as a seven-year-old child for severe anxiety states and unaccountable rages, may help to illustrate the capacity to keep trying to understand that we found to be characteristic of those adults who had been in therapy as children:

\section{How do you think these experiences with your parents have affected your adult} personality? Well. (laughs) Well I find it very difficult to know what's cause and what's effect. Was I just like that all the way along or did I ...? I think I have always worried about upsetting people, offending people. I don't know whether that the way my.... I think I was like that when I was a child. And I don't know whether that was something that my parents did or if it was how they reacted to the just the way I was. I would sort of - sorry - about upsetting people. A lot of the sort of cleanliness obsessions went away 
while I was coming here. So it probably helped. I think the general feeling of threat and insecurity I think picked up from... my parents. Not exactly from what they did but just from what they were. From what had happened to them. Because ......

When you say what happened to them what are you thinking about? Well I am thinking about my father's childhood in [Jewish ghetto in middle Europe]. Where his parents were very, very frightened and they had to ... his father, he and his mother left go for England on the last boat out. And his father was in a concentration camp. But managed to escape. Not ... but not. So my father had all this sort of anxiety and worry. I think he is a great worrier and ... So although these things didn't directly happen to me. The, I think the atmosphere of, worry of things happening that I didn't understand. And people behaving in strange ways that I didn't understand. Er ... I was a bit sensitive or picked these things up. Er ... that's probably made me feel more twitchy, less secure, less able to do what, less confident I guess than I might have been otherwise.

The collection of data for the quantitative long-term follow-up study suffered from a number of limitations, especially because we found it much harder than expected to recruit an adequate sample to test our hypotheses. The results referred to above were statistically significant or almost so, but many fascinating comparisons could be looked at only in terms of trends given unequal group sizes (untreated but referred individuals were generally unwilling to undergo extensive interviews, while the siblings of treated children - who had not been referred for help as children - were often the most enthusiastic about getting their chance to talk!). Our study also demonstrated to us that, no matter how complex and timeconsuming the quantitative measures were, they inevitably failed to represent some of the richness of personal lives that makes the psychoanalytic study of subjectivity uniquely valuable scientifically. For example, the richness of the extract above is reduced to numbers across a transcript in the AAI coding, with all content lost. It was in this study that our group, joined most creatively by Dr Nick Midgley, began to explore the use of parallel qualitative methods (Interpretive Phenomenological Analysis) within a quantitative outcome study, to enrich the findings and our understanding of them (Midgley and Target, 2005; Midgley, 
Target, \& Smith, 2006). That strategy, again led by Nick Midgley, has been much further and most fruitfully developed in the IMPACT-ME study, described later.

Over the 25-year period, much greater trust has grown within the child psychotherapy profession (which is rooted in the public sector, whereas child psychoanalysis itself is almost entirely a private practice and remains largely insulated from empirical research). An acceptance of the particular benefits and lessons of such research has replaced resistance and led many leaders of the profession to be interested, optimistic and committed participants, and some leaders in the world of treatment research to collaborate throughout our programme of work, as will be described.

\section{(2) Designing and validating new outcome measures, piloting a Randomised}

\section{Controlled Trial (RCT) protocol and making the case for funding}

The strictest method of evaluation of therapeutic outcome, required by the evidence-based guidelines in the wider mental health community and by public funding is the RCT. I hope to show later the creativity of using mixed methods to give the greatest external as well as internal scientific validity, and to put the flesh of clinical meaning on the bones of quantitative outcomes, however the most fruitful approach is I think to combine these within an RCT framework. As stated earlier, there are particular practical and ethical difficulties in using RCTs to evaluate intensive, long-term therapies. These include the identification of outcome measures appropriate to psychoanalytic treatment, the need for lengthy follow-up to demonstrate changes in personality functioning and the apparent "sleeper effect", difficulties in describing complex treatment procedures sufficiently clearly for others to be able in principle to replicate the study, and the very great expense of mounting an investigation with sufficient statistical power to produce conclusive results. Alongside the adult follow-up of historical cases, described above, we recruited a team led by Dr Karin Ensink, to overcome the barriers to setting up an RCT. There were four main areas of preparation: 


\section{(a) Measurement of outcome}

We accepted that measures applied in the evaluation of other therapies, such as change in symptoms and diagnosis, must be included when assessing the outcome of psychoanalytic therapy. However, if one is to test the belief that psychoanalytic treatment does more than reduce observable symptoms, that it also improves long-term adjustment - justifying its greater cost and demand on families - then we needed to measure parameters identified by analysts as relevant, such as the quality of relationships, regulation of affect, social maturity, and understanding. The approach we took was to make use of recent progress in developmental psychology and develop a battery of measures devised to chart the cognitive and social development of children, and then collect normative data by using these measures. The main measures developed were:

(1) The HCAM (Target, Fonagy, Schneider, Ensink, \& Janes, 2000), which is a measure of social and emotional adaptation (conceptually based on Anna Freud's developmental lines) scored for 14 different domains, using different norms for five developmental levels. This measure has been adapted for digital profiling of adaptation and symptoms in varying contexts (Barber, Target, Fonagy, Katsavdakis, \& Clifford, 2001), and was one of the measures used in the later IMPACT study (see below), to capture functioning across domains.

(2) A version of the MacArthur Story Stem Battery (Oppenheim, Emde, \& Warren, 1997), developed by Jill Hodges and her team (Hodges, Steele, Hillman, Henderson \& Kaniuk, 2003) as an assessment of the internal world and representations of self and other using a doll-play story completion paradigm, which we extended and manualized for school-aged children. 
(3) The Child Attachment Interview (Target, Shmueli-Goetz \& Fonagy, 2003), a new measure of child-parent attachment, which we extensively validated (Shmueli-Goetz, Target, Fonagy \& Datta, 2008).

(4) The Affect Task, an existing measure of emotion attribution and understanding, developed for preschool children by Miriam Steele, Peter Fonagy, and Howard Steele (Steele, Steele, \& Croft, 2008), and adapted and validated in this project for children of elementary-school age.

(5) We also included an advanced theory of mind task, the Happé Strange Stories (Happé, 1994), and the Fischer Mean-and-Nice Stories (Fischer, Bullock, Rotenberg, \& Raya, 1993), to look at cognitive mentalizing and moral understanding in this age range.

Measures were validated within a battery including widely used and already wellstandardized outcome measures such as the Child Behavior Checklist (CBCL; Achenbach \& Edelbrock, 1981) and Schedule for Affective Disorders and Schizophrenia for School-Age Children (K-SADS; Chambers et al., 1985), on a clinical sample of 80 children aged 6-11 years recruited from referrals to Child and Adolescent Mental Health Consultation Services, and 80 normal controls. The test-retest and inter-rater reliability data of the measures were good. There were significant differences in the performance of referred and non-referred children on all the measures, and the measures and full battery were acceptable to a clinical population. These measures have continued to be developed and applied by other research groups, with our support, to varying clinical populations (e.g. Ensink, Normandin, Target, Fonagy, Sabourin \& Berthelot, 2015; Humfress, O'Connor, Slaughter, Target \& Fonagy, 2002; Joseph, O'Connor, Briskman, Maughan \& Scott, 2014).

(b) The specification of treatment technique, or manualization

Although there was a vast literature on technique in adult and child psychoanalytic treatment, 
this was not written in the operational terms that are required to define a treatment approach in studies of efficacy. We worked with a group of senior child psychoanalysts and scholars to prepare a manual of the approach that had evolved at the Anna Freud Centre for long-term, intensive psychoanalysis with school-age children suffering with developmental and neurotic disorders (Fonagy, Edgcumbe, Target, Miller, \& Moran, 1996, unpublished manuscript) ${ }^{3}$. This form of treatment aims to resolve emotional or behavioural symptoms, and developmental delays and deviations, through exploring unconscious conflicts which may have generated them. Through observing patterns of relating to the therapist, including play and interaction, the therapist tries to understand with the child what conflicts - fears or wishes, for example about aggression, separation, competition, entering adolescence - may underlie some of the problems they have brought. As therapy proceeds these conflicts may become focused on the therapist and be 'interpreted in the transference', which allows them to be recognised very directly and in a way that may enable rapid change. Of the 17 chapters of the manual, 5 provide historical and theoretical background, and 12 cover an important aspect of technique, offering a definition, the aims the analyst would have in mind in using that form of intervention, the ways in which it is implemented, and finally, situations in which it is not likely to be helpful. The manual drew extensively on the many years of work to systematize child psychoanalytic treatment at the Centre, especially the Hampstead Index Project (Sandler, 1962). It covered mainly classical psychoanalysis, but also developmental help and work with parents, both of which had been shown to be crucial in predicting good outcomes in the retrospective study. Validation of the manual was carried out by subjecting individual chapters to formal assessments of clarity, accuracy, and comprehensiveness with current senior and junior clinicians at the Anna Freud Centre. Sadly, the manual was never

\footnotetext{
${ }^{3}$ This manuscript is available from the author of this paper.
} 
submitted for publication, and we used a different manual developed with a wider group in our eventual RCT study (IMPACT), but it was a major, earlier step in our process of articulating the underlying model of psychoanalytic child therapy.

\section{(c) Process assessment and monitoring of treatment integrity}

As well as specifying the technique involved in this treatment, we needed to devise measures of the content and technique of analytic sessions in order to learn to what extent the technique described in the manual was in fact being used. This involved piloting the recording of sessions to assess process variables and check adherence and competence. We videotaped analytic sessions on the basis that it would be vital to see action as well as hear words and other sounds. At the time this was regarded as intrusive and perhaps incompatible with analytic work. However, group discussion of the tapes with the therapists, supervisors, and researchers showed fascinating advantages of taping over therapists' subsequent process notes; not surprisingly, given what we know of memory and what analysts believe about unconscious editing, the tapes consistently revealed key aspects of session process that the therapists had forgotten. Incidentally, although one of the objections to recording was that parents and children would not consent, this turned out to be rare, and was in fact more commonly an issue for therapists, who, however, tended to become more accepting as they saw what could be learned clinically, separately from the research requirement for monitoring treatment fidelity.

We also needed to develop scales for coding the process of treatment. We developed a measure named the Session Rating Scale (Fonagy \& Target, 1997b), which attempted to quantify in extensive detail the psychoanalytic experience of children treated at the Anna Freud Centre. The scale provides a measure based on observer ratings (from tape-recorded sessions) of the content and quality of the work with each patient, which may help to identify 
what type of treatment was most successful in a given type of case. It also offers a way of excluding cases where the therapeutic work, for whatever reason, was not within the range of accepted psychoanalytic technique as defined in the manual. However, anyone who has used this measure would attest to its overwhelming length and detail; we learned from this in tackling the IMPACT study (described later)!

\section{(d) Proposal for a prospective study of child psychoanalytic psychotherapy}

In a team led by Dr Karin Ensink, we successfully piloted the protocol for a full RCT of the outcome of child psychotherapy, comparing it to both the best-validated alternative treatment (cognitive-behavioural therapy; CBT) and a "treatment as usual" control (ordinary clinic practice, which was usually short-term family work). However, that led to one of the more sobering findings in our programme of work: No-one was very interested in the answer to the research question!

The responses from several large and smaller funders, both public and private, were consistent: that, while the prospective study was well-designed and feasible, and proposed by a credible research group, in their opinion it was not interesting enough to know whether psychoanalytic child psychotherapy worked. The argument was accepted that this was a widely provided form of treatment, with training in the UK publicly funded, but without an adequate evidence base. However, the implied message from the reviews was that everyone knew that even if psychoanalytic child psychotherapy was effective, it was most unlikely to be cost-effective, and anyway the tide was running in favour of short-term, symptom-focused therapies with a straightforward rationale and a shorter training.

This is where the commitment and/or masochism of the researcher comes into its own. Undaunted (on a good day), we pressed on, on three main fronts: 
- Establishing the developmental and clinical theory of mentalizing as a mechanism of psychotherapies

- Developing shorter-term, more focused treatments based on this theory

- Developing credibility within the main bodies defining the evidence base, and establishing the research case there.

\section{(3) Developing a theoretical model of mental development: diagnostic difference} pointing to a key developmental capacity and a core technique

Our work on the retrospective study, in conjunction with reviewing clinical outcomes prospectively, led our group to extend theoretical assumptions about psychic change in child psychotherapy (e.g. Fonagy, Moran, Edgcumbe, Kennedy, \& Target, 1993). We delineated two models of the psychoanalytic treatment of emotional disturbance in children. The first (the classical model) involved the patient recovering threatening ideas and feelings, which had been repressed or distorted as a result of conflict and defence. Non-intensive and intensive treatments seemed to be equally effective for this group, although for younger children intensive treatment had a greater advantage. The second model (which we called the mental process model) drew attention to inhibited fundamental mental processes. These models had been clearly foreshadowed in earlier clinically-based diagnostic and technical developments at the Anna Freud Centre, in distinguishing between 'classical analysis' most suited to a neurotic child, and 'developmental help', also intensive and prolonged but with a focus on 'ego development', for example focusing on developing social and cognitive capacities to support affect regulation, rather than on interpretation of conflict (Hurry, 1998). The gradual engagement of these processes in treatment occurred primarily through the patient and analyst focusing on the thoughts and feelings of each person, and how the child understood these. Patients with disorders that involved the inhibition of essential mental processes, such as the reflective capacity of mentalizing (rooted in attachment experiences), 
showed more pervasive psychopathology, and appeared to require intensive psychoanalytic intervention in order to show good outcomes. This distinction roughly corresponded to the traditional psychoanalytic distinction made by Anna Freud's colleagues of neurotic versus developmental disorder (Rosenfeld \& Sprince, 1963), but from the retrospective study, we reached a clearer definition of such disorders in diagnostic terms and confirmed the theoretical expectation that those patients with mental process disorders appeared to need long-term and intensive intervention.

Through study of the therapeutic process records we were able to delineate the technique most effective for the different groups of cases, and to develop a model of mentalizing, or understanding behaviour as reflecting mental states in self and other, which could be formulated as a normal developmental process (Fonagy, Gergely, Jurist \& Target, 2002), a mechanism of therapeutic action, and an outcome measure.

This linked up to quite separate earlier research efforts by the same group with colleagues Miriam and Howard Steele, on the prenatal predictors of intergenerational attachment security in babies. It had emerged unexpectedly that an even stronger predictor of infant security than attachment security of each parent was the mentalizing capacity of each parent when they discussed their own childhood experiences early in the pregnancy (e.g., Fonagy, Steele \& Steele, 1991). This finding has been replicated, and the centrality of mentalizing as a deficit in developmental and personality disorders has also been extensively empirically documented, including by our group (e.g., Fonagy \& Target, 2000, 2006).

The development of a theory of mentalizing, although conceptually rooted in major psychoanalytic developmental theories (of Winnicott, Bion, ego psychology and the French psychosomatic school), had a mixed reception within psychoanalysis, often being said to be too psychological and too research-linked. Our group has always seen links to evidence from psychology, psychiatry and neuroscience as positive, but like attachment theory, the model of 
mentalization has found greater enthusiasm outside psychoanalysis than within it, where they both began. There is a tendency within psychoanalysis to state that only "pure" belief in psychoanalysis is real psychoanalysis, that a psychoanalyst who thinks that empirical sciences and other therapeutic modalities are models with substantial merits, which can complement psychoanalysis, is not a "real" psychoanalyst. That anything fundamental about psychopathology must be within psychoanalytic theory and nowhere else - hence the accusations familiar to pioneers such as Peter Fonagy or John Bowlby, that on the one side their contributions are not psychoanalytic, and on the other that much better analysts have already made them, they are already known to everyone and part of the theory. Over the decades, there has been a clear sea-change of attitudes from our colleagues, from seeing both research and ideas about mentalizing as non-analytic and threatening, to increasing appreciation and participation in both. Perhaps the annoying piece of equipment cluttering up the ship can become valued over time, when there is need for a bridge, or possibly a lifeboat!

\section{(4) Developing new treatment models coherently based on this theory}

We were conscious that full psychoanalysis, or even psychoanalytic psychotherapy, would never be widely available to meet the needs of children with emotional and developmental disorders, and indeed that such an intensive therapy placed great demands on families and overstretched services. Over the past 15 years we have developed, in addition to Bateman and Fonagy's very well-evidenced Mentalization-Based Treatment (MBT) for borderline personality disorder (see Bateman \& Fonagy, 2016), a MBT for families (MBT-F; Asen and Fonagy, 2012; Fearon et al., 2006), and a mentalization-based systemic model developed to manage hard-to-reach adolescents, known as AMBIT (Bevington, Fuggle, Fonagy, Target \& Asen, 2013). Most recently, the next generation of our group, with international colleagues, have developed an individual child MBT (MBT-C; Midgley, Ensink, Lindqvist, Malberg \& 
Muller, in press; Midgley \& Vrouva, 2012). The rigorous evaluation of these clinically and theoretically credible adaptations of MBT for personality disorders is currently being undertaken by the next generation, while we have persisted in trying to assess the value of psychoanalytic psychotherapy itself, as the form of psychoanalytic treatment most widelypractised, and an important alternative model to CBT and medications.

\section{(5) Establishing credibility within the field of child mental health outcomes}

Probably the central plank of the bridge towards our getting support for a large-scale RCT including child psychotherapy was broader work on systematic reviewing of the evidence base of interventions for childhood mental health problems, establishing credibility for our group as competent outcome researchers familiar with the methodological challenges and as able as other outcome researchers to be objective about our preferred approach. An early step in this process was to produce a child version of the influential review of mental health treatments, What Works for Whom? (Roth \& Fonagy, 1996, 2005). The chapter of that volume covering treatments for children (Target \& Fonagy, 1996) was subsequently developed with colleagues into a book, What Works for Whom? A Critical Review of Treatments for Children and Adolescents (Fonagy, Target, Cottrell, Phillips \& Kurtz, 2004). This and other work for national mental health policy bodies led to the appointment of Peter Fonagy as Chair of the NICE GDG on depression in young people, published in 2005 and updated in 2015 (NICE, 2005, 2015). The GDGs provide strong evidence-based guidance for all publicly funded healthcare in the UK. I was appointed Chair of the Psychotherapies Section, covering all psychological treatments. We systematically reviewed the literature, across therapies, and included the preliminary evidence of effectiveness of psychoanalytic psychotherapy (Trowell et al., 2002, and the pre-publication findings of Trowell et al., 2007), together with the non-RCT evidence described above. The 2005 Guideline recommended, for 
moderate to severe depression, or mild depression not responding to brief symptom-focused treatment, a stepped-care model in which individual psychoanalytic child psychotherapy (approximately 30 weekly sessions) would be considered by a multidisciplinary team if shorter, more symptom-specific treatments such as CBT had been tried without success. Given the widespread current, public practice of individual child psychotherapy, and the preliminary evidence of benefit, the first research recommendation in the guideline was that:

An appropriately blinded, randomised controlled trial should be conducted to assess the efficacy (including measures of family and social functioning as well as depression) and the cost effectiveness of individual CBT, systemic family therapy and child psychodynamic psychotherapy compared with each other and treatment as usual in a broadly based sample of children and young people diagnosed with moderate to severe depression (using minimal exclusion criteria). (NICE, 2005, p. 40)

This recommendation released the large-scale government funding for an RCT of psychoanalytic child psychotherapy in comparison with CBT and high-quality clinical management (funding was, unfortunately, insufficient to include family therapy as the guideline had recommended). It was important to work under the leadership of an acknowledged expert in evaluating the outcomes of treatment across different treatment modalities, who could not be accused of bias towards psychoanalytic psychotherapy. Such a person was Professor Ian Goodyer of the University of Cambridge, who led a large group of Principal Investigators covering the various modalities, geographical regions, and specialized research skills such as health economics and brain imaging. The study design is detailed in Goodyer et al. (2011) and will not be repeated here; instead, I will retain focus on the story of evaluating psychoanalytic psychotherapy. Dr Nick Midgley has played a key role in this arm of the IMPACT study, and led its qualitative sub-study (IMPACT-ME), to be described briefly later in this account, together with a sketch of the findings. 


\section{(6) Finally! Designing and conducting a major randomized controlled trial (RCT)}

\section{including psychoanalytic psychotherapy, using quantitative and qualitative}

\section{methodologies}

Carrying out the child psychotherapy arm of the IMPACT study has involved further work on the issues described above, but beyond the Anna Freud Centre, in collaboration with child psychotherapists. A group of leading UK child psychotherapists produced a new manual for Short-Term Psychoanalytic Psychotherapy (STPP) in the treatment of adolescent depression (Cregeen, Hughes, Midgley, Rhode \& Rustin, 2016). This manual was written quite separately from the child psychoanalysis manual described earlier, and was based on a different but overlapping theoretical base, on the common ground between the Kleinian Tavistock approach and the Anna Freudian approach outlined above (the Tavistock approach is probably more prevalent in the National Health Service where the study was to be implemented). It was focused on conflict, defence and object relations, not on mentalization specifically. The model was structured around up to 28 weekly sessions, plus 7 parent sessions with a separate therapist, both delivered by highly trained child psychotherapists, or child mental health professionals such as psychiatrists under close supervision of a child psychotherapist. While having elements of contemporary technique at the AFC, we therefore sacrificed some of the work done on technique and theory before, for the great gain of collaborating closely with the main training organisation - the Tavistock Clinic, which provides most training for child psychotherapists in the NHS - and a large proportion of the child psychotherapists working in the public health system in the UK.

In the IMPACT study, we used audio taping rather than video recordings of all sessions with the adolescent patients, video recording would have been impractical (and probably not acceptable) in the many community clinic settings where treatments were provided. This allowed us to study session process, as well as being necessary to check the integrity of treatments in all modalities. Interestingly, by the time of this study, 15 years after 
the pilot work was started, taping of sessions seemed to be quite easily accepted by psychoanalytic psychotherapists. We used the Comparative Psychotherapy Process Scale (CPPS) to assess the degree to which a therapist used techniques of psychodynamicinterpersonal therapy and/or CBT in an entire psychotherapy session (Hilsenroth, Blagys, Ackerman, Bonge, \& Blais, 2005). In an additional study, our group - a talented $\mathrm{PhD}$ student of Nick Midgley and myself, Ana Calderon, with collaboration from Celeste Schneider, the developer of the Child Psychotherapy Q-Set (CPQ) - undertook the development of an adolescent version of Enrico Jones's Psychotherapy Process Q-Set, the APQ. This provides a way to characterise individual sessions of an adolescent therapy and its progress over time in clinical terms that are quantitatively analysable. It can also be used in different forms of treatments, and indeed Calderon's work showed that the APQ distinguished between the techniques of therapists conducting CBT versus psychoanalytic psychotherapy, and that these differences corresponded in predicted ways to the appropriate CPPS scales (Calderon, Schneider, Target, \& Midgley, 2017). We therefore have a way in the future to relate content and technique in these sessions (which have been shown to be adherent to their manualized models) to the individual patients' outcomes.

As mentioned above, another very exciting add-on study, IMPACT-ME (My Experience), conceived and led by Dr Nick Midgley and me, similarly gives the opportunity to extend, deepen, and better understand the quantitative results, by using qualitative interview methodology. This longitudinal study involved in-depth semi-structured interviews with young people, parents, and therapists participating in the IMPACT trial (Midgley, Ansaldo and Target, 2014). The interviews addressed the experience and understanding of depression, hopes and fears about treatment, and how things looked after treatment had been offered and taken up (or sometimes dropped out of). Giving the participants a voice on these central subjects, allowing them to provide their own interpretations of their own experiences 
and "results" may, as we join the quantitative and qualitative findings together across individuals (Parkinson, Eatough, Holmes, Stapley \& Midgley, 2016), give us the strongest handle on what can lead to positive change, and sticking with treatment, or may on the other hand leave the young person still facing what might be a life sentence of disabling depression. So far, papers have addressed the following topics from interviews: the experience of depression (Midgley et al., 2015); where depression has come from (Midgley et al., 2017); experience of treatment (Midgley, Holmes, et al., 2016); experience of participating in an RCT (Midgley, Isaacs, Weitkamp, \& Target, 2016); and experience of being a parent of a depressed adolescent (Stapley, Target, \& Midgley, 2016, 2017). Many further questions are to be explored from the very large set of often rich interviews.

The IMPACT study has recently released its first overall results (Goodyer et al., 2016). Of the 465 participants who entered the study, $84 \%$ were retained to follow up. STPP, CBT, and the high-quality manualized reference "brief psychological intervention" (a kind of ideal "treatment as usual" within a multidisciplinary team, most often delivered by a child psychiatrist) were associated with broadly similar reductions in depressive symptoms, and there were no significant differences in terms of cost-effectiveness; young people had on average about $50 \%$ reduction in symptoms 12 months after the end of therapy, and $77 \%$ were in remission. While this is in one way a great result for STPP - it stood up absolutely as well as the most "credible" treatments, CBT and psychiatric management, in terms of outcomes for moderate to severe clinically referred depression, and although patients attended more sessions, it was not significantly more expensive - the study was limited by the ethical requirement not to have a placebo or no-treatment comparison. Depression is well known to be an episodic, recurrent condition for many sufferers, and some improvement a couple of years after a very low period (leading to referral) would be expected. The challenge to specify and demonstrate the added value from a deeper, less easily grasped and often longer 
therapeutic approach, showing a greater or broader immediate benefit or long-term resilience - remains there for the generation now in their research prime and for their students currently engaging with these issues for their first time.

\section{Concluding thoughts: $20 / 20$ hindsight}

Here, I will step back from the specific questions Peter Fonagy and I and many colleagues and graduate students have wrestled with.

\section{Some unsolicited tips}

First, some brief, informal thoughts that I wish I had had earlier in this long programme of research, and which might be relevant to readers at an earlier stage:

- Of course read and think about all relevant literature so that the specific research questions are clear and timely.

- Have a deep rooting in and respect for the therapy or all therapies being evaluated. I have always believed that a range of different theoretical approaches and forms of intervention (e.g. at the level of family, parent or school, not only for an individual child) have value, and that a range of options is necessary to enable most children struggling with mental health to access help they can use. Researchers in outcome studies must work closely and effectively with clinicians, this needs trust and openness to questioning in both directions.

- Mixed methods strengthen findings: there is complementarity of quantitative and qualitative methods, and conceptual-clinical and developmental methods which is not a luxury, we need this

- Think about revision of theory and technique alongside outcomes, I think this applies to all modalities 
- Everything takes twice as long (or longer) and costs twice as much (or more) than expected

- If possible, engage senior researchers to inform the design and oversee the conduct of the studies. We were blessed with the ideas and encouragement of researchers of the distinction of Professor Alan Kazdin, Professor Donald Cohen and Professor Sir Michael Rutter, at crucial early stages of working on methods, as well as the leadership of Professor Ian Goodyer in the eventual IMPACT study. Their experience, challenges and guidance make all the difference especially at key stages of a long programme.

- Have brilliant, warm and charismatic organisers as fellow PIs

- $\quad \mathrm{PhD}$ students can be a smart, fun, and creative workforce - but need plenty of mentoring plus a well-oiled team

- Plan a timeline of publications alongside theory development and data collection, to maintain momentum, allow other groups to contribute and avoid clogging the desk drawer(s)

\section{Possible fertile questions from here}

Can we now answer the "what works for whom" question? Not yet, and it is the key one. With hindsight, perhaps the field got bogged down in the "horse-race" mentality, which treatment is best? Clinicians with training in different modalities, or theorists and researchers with favoured approaches, got into competitively growing their evidencebases. However, a little clinical reflection suggests that a variety of approaches can help a child or family, depending on several factors (for example the way of thinking about their problems that makes most sense to them, how engaged the school and family are able to be, the age of the patient, and which approach the most authoritative or charismatic clinician is offering - we need to respect and include the placebo effect, not dismiss it). The IMPACT study showed that the three most commonly offered treatments in UK public child mental health all worked to a similar and encouraging 
extent, and had similar costs. Perhaps our IMPACT-ME add-on will allow us, as we integrate quantitative and qualitative data, to disentangle who stuck with and benefitted from which approach, and why (in the view of child, parent and therapist).

Can we "bottle" one effective ingredient, which we have theorized as the enhancement of mentalizing within a therapeutic attachment relationship? Could that be delivered in a briefer and more collaborative, transparent framework? As I have briefly described, our group has developed several models to do this for different referral problems and contexts, and we have learned some lessons but certainly not done most of what is required. It may be worth sharing the observation that mentalization-based treatments may not work best by explicitly aiming to increase mentalizing. Children and families (like adults) come for help because they are distressed about something unbearable, not because they want to learn a skill. Helping them develop more understanding and perspective on what is distressing is probably a more mentalizing and effective approach than tackling the perceived deficit (of mentalizing) as an extra problem. How much can we learn from studying session process and relating it to outcomes? This is an area that has been studied more fully in relation to other therapies. The data in the IMPACT study allow us to compare session processes in three modalities already shown to be quite distinct. Relating measures of in-session process, and changes across sessions, may greatly increase our understanding of what is helping or hindering development and reduction of symptoms.

Can we further the development of measures of adaptation and functioning, so that the emphasis is less on symptoms of "illness"? Our effort in this direction, the HCAM, tried to distinguish 14 domains of normal and abnormal development which could be tracked cross-sectionally and longitudinally, going well beyond symptoms to cover things like the child's capacity to have relationships, to play, learn, look after himself physically, regulate moods, manage stress and so on. That work is relevant to adult as well as child well-being and psychopathology, and while inevitably very complex it seems worth trying to take further.

Can we prioritise attention to what patients (and significant others) think and feel about what we offer? At the most basic level, if we are not providing something that makes sense to the service user, they are not likely to use it (or, if free to choose, attend at all), even if it is based on a valid theory of psychopathology. Traditionally psychoanalytic practitioners tended to 
believe that they knew better than the patient what was going on and what was needed, and that the patient would, for unconscious reasons, be likely to resist changes of thinking and behaviour (implicitly discrediting their viewpoint except as a symptom). The theory of mentalizing (within a trustworthy attachment) leads us - like other collaborative therapy models - to the therapeutic alliance, an alliance based on feeling understood by the therapist, and able to understand what he/she is doing and why. Recent developments in mentalizing theory have elaborated the key concept of "epistemic trust" (Fonagy and Allison, 2014), according to which a baby or child (or an adult in a dependent relationship) will learn from and follow someone to the extent that the relationship has provided a sufficiently secure attachment, reliable and attentive to the individual's experience. It seems to me that child therapy techniques in general have changed rather as educational styles and social attitudes have changed, placing greater weight over the decades on the child's perspective and on modelling communication and thoughtful collaboration, and less on giving information and instructions. Similarly, our research techniques as well as our theoretical framework involve listening more to the voice of the child, rather than on telling him/her what they think, what is wrong, and what they need. As a trainee clinician 40 years ago, I remember reading books by patients, and papers about patients' experiences. It seemed that usually the most and least satisfied patients contributed to those books, and that they did not always give a balanced picture. But I recognized then that their subjectivity is at the centre of the picture, the whole point of it, and if we as clinicians or researchers get more focused on our own methods and careers than on what our patients experience, we lose our way. 
Finally, I would like to thank the editors of this Special Issue for focussing on the pleasures and pitfalls of long-term programmes. I trust that some points will have been applicable to readers across the field. 


\section{References}

Achenbach, T. M., \& Edelbrock, C. S. (1981). Behavioral problems and competencies reported by parents of normal and disturbed children aged four through sixteen. Monographs of the Society for Research in Child Development (1981), 1-82.

Asen, E., \& Fonagy, P. (2012). Mentalization-based therapeutic interventions for families. Journal of Family Therapy, 34, 347-370. doi: 10.1111/j.1467-6427.2011.00552.x

Barber, C. C., Target, M., Fonagy, P., Katsavdakis, K., \& Clifford, P. (2001). Children's FACE: A Comprehensive Developmentally-tailored Rating System for Children and Adolescents (1). Topeka, KS: The Menninger Clinic, Research Department.

Bateman, A \& Fonagy, P. (2016). Mentalization Based Treatment for Personality Disorders: A Practical Guide. Oxford, UK: Oxford University Press.

Bevington, D., Fuggle, P., Fonagy, P., Target, M., \& Asen, E. (2013). Innovations in Practice: Adolescent Mentalization-Based Integrative Therapy (AMBIT) - a new integrated approach to working with the most hard to reach adolescents with severe complex mental health needs. Child and Adolescent Mental Health, 18, 46-51. doi: 10.1111/j.1475-3588.2012.00666.x

Bifulco, A., Brown, G. W., Moran, P., Ball, C., \& Campbell, C. (1998). Predicting depression in women: The role of past and present vulnerability. Psychological Medicine, 28, $39-50$.

Calderon, A., Schneider, C., Target, M. \& Midgley, N. (2017). The Adolescent Psychotherapy Q-Set (APQ): A validation study. Journal of Infant, Child and Adolescent Psychotherapy, 16, 106-120.

Chambers, W. J., Puig-Antich, J., Hirsch, M., Paez, P., Ambrosini, P. J., Tabrizi, M. A., \& Davies, M. (1985). The assessment of affective disorders in children and adolescents by semistructured interview: test-retest reliability of the Schedule for Affective Disorders and Schizophrenia for School-Age Children, Present Episode Version. Archives of General Psychiatry, 42, 696-702.

Cregeen, S., Hughes, C., Midgley, N., Rhode, M., \& Rustin, M. (2016). Short-term psychoanalytic psychotherapy for adolescents with depression: A treatment manual. (Ed. J. Catty). London, UK: Karnac Books.

Ensink, K., Normandin, L., Target, M., Fonagy, P., Sabourin, S., \& Berthelot, N. (2015). Mentalization in children and mothers in the context of trauma: An initial study of the 
validity of the Child Reflective Functioning Scale. British Journal of Developmental Psychology, 33(2), 203-217. doi:10.1111/bjdp.12074.

Fearon, R. M. P., Target, M., Fonagy, P., Sargent, J., Williams, L., \& Bleiberg, E. (2006). Short-term mentalizing and relational therapy: An integrative family therapy for children and adolescents. In E. Bleiberg, \& P. Fonagy (Eds.), Handbook of mentalization-based treatment (pp. 201-222). Chichester, UK: Wiley.

Fischer, K. W., Bullock, D., Rotenberg, E. J., \& Raya, P. (1993). The dynamics of competence: How context contributes directly to skill. In R. H. Wozniak \& K. W. Fischer (Eds.), Development in context: Acting and thinking in specific environments (pp. 93-117). Hillsdale, NJ: Lawrence Erlbaum Associates.

Fonagy, P., \& Allison, E. (2014). The role of mentalizing and epistemic trust in the therapeutic relationship. Psychotherapy, 51, 372-380. doi: 10.1037/a0036505

Fonagy, P., Edgcumbe, R., Target, M., Miller, J., \& Moran, G. (1996). Psychodynamic Child Therapy: Theory and Technique. Unpublished manuscript, The Anna Freud Centre and University College London, London, United Kingdom.

Fonagy, P., Gergely, G., Jurist, E. J., \& Target, M. (2002). Affect regulation, mentalization and the development of the self. New York, NY: Other Press.

Fonagy, P., Moran, G. S., Edgcumbe, R., Kennedy, H., \& Target, M. (1993). The roles of mental representation and mental process in therapeutic action. Psychoanalytic Study of the Child, 48, 9-48.

Fonagy, P., Steele, H., \& Steele, M. (1991). Maternal representations of attachment during pregnancy predict the organization of infant-mother attachment at one year of age. Child Development, 62, 891-905. doi: 10.1111/j.1467-8624.1991.tb01578.x

Fonagy, P., Steele, M., Steele, H., Higgitt, A., \& Target, M. (1994). The Emanuel Miller Memorial Lecture 1992. The theory and practice of resilience. Journal of Child Psychology and Psychiatry, 35, 231-257.

Fonagy, P., \& Target, M. (1994). The efficacy of psychoanalysis for children with disruptive disorders. Journal of the American Academy of Child and Adolescent Psychiatry, 33, 45-55. doi: 10.1097/00004583-199401000-00007

Fonagy, P., \& Target, M. (1996). Predictors of outcome in child psychoanalysis: A retrospective study of 763 cases at the Anna Freud Centre. Journal of the American Psychoanalytic Association, 44, 27-77. doi: 10.1177/000306519604400104

Fonagy, P., \& Target, M. (1997a). Attachment and reflective function: Their role in selforganization. Development and Psychopathology, 9, 679-700. 
Fonagy, P., \& Target, M. (1997b). Approaches to the evaluation of outcome in psychoanalysis. Psychoanalytic Inquiry, 17, 58-73.

Fonagy, P., \& Target, M. (1998). Mentalization and the changing aims of child psychoanalysis. Psychoanalytic Dialogues, 8, 87-114. doi: $10.1080 / 10481889809539235$

Fonagy, P., \& Target, M. (2000). The place of psychodynamic theory in developmental psychopathology. Development and Psychopathology, 12, 407-425. doi: $10.1017 /$ S0954579400003084

Fonagy, P., \& Target, M. (2006). The mentalization-focused approach to self pathology. Journal of Personality Disorders, 20, 544-576. doi: 10.1521/pedi.2006.20.6.544

Fonagy, P., Target, M., Cottrell, D., Phillips, J., \& Kurtz, Z. (2004). What works for whom? A critical review of treatments for children and adolescents. New York, NY: Guilford Press.

Freud, A. (1976). Changes in Psychoanalytic Practice and Experience. International Journal of Psycho-Analysis, 57, 257-260.

George, C., Kaplan, N., \& Main, M. (1985). Attachment interview for adults. Unpublished manuscript, University of California, Berkeley.

Goodyer, I. M., Reynolds, S., Barrett, B., Byford, S., Dubicka, B., Hill, J., . . Fonagy, P. (2016). Cognitive behavioural therapy and short-term psychoanalytical psychotherapy versus a brief psychosocial intervention in adolescents with unipolar major depressive disorder (IMPACT): A multicentre, pragmatic, observer-blind, randomised controlled superiority trial. Lancet Psychiatry. doi: 10.1016/S2215-0366(16)30378-9

Goodyer, I. M., Tsancheva, S., Byford, S., Dubicka, B., Hill, J., Kelvin, R., . . Fonagy, P. (2011). Improving mood with psychoanalytic and cognitive therapies (IMPACT): A pragmatic effectiveness superiority trial to investigate whether specialised psychological treatment reduces the risk for relapse in adolescents with moderate to severe unipolar depression: study protocol for a randomised controlled trial. Trials, 12, 175. doi: 10.1186/1745-6215-12-175

Happé, F. G. E. (1994). An advanced test of theory of mind: Understanding of story characters' thoughts and feelings by able autistic, mentally handicapped, and normal children and adults. Journal of Autism and Developmental Disorders, 24, 129-154. doi: 10.1007/BF02172093. 
Heinicke, C. M. \& Ramsey-Klee, D. M. (1986). Outcome of child psychotherapy as a function of frequency of session. Journal of the American Academy of Child and Adolescent Psychiatry, 25, 247-253. doi: 10.1016/S0002-7138(09)60233-8

Hill, J., Fudge, H., Harrington, R., Pickles, A., \& Rutter, M. (1995). The Adult Personality Functioning Assessment (APFA): Factors influencing agreement between subject and informant. Psychological Medicine, 25, 263-275. doi: 10.1017/S0033291700036163

Hilsenroth M. J, Blagys M. D., Ackerman, S. J., Bonge, D. R., Blais, M. A. (2005). Measuring psychodynamic-interpersonal and cognitive-behavioral techniques: Development of the Comparative Psychotherapy Process Scale. Psychotherapy: Theory, Research, Practice, Training, 42, 340-356. doi: 10.1037/0033-3204.42.3.340

Hodges, J., Steele, M., Hillman, S., Henderson, K., \& Kaniuk, J. (2003). Changes in attachment representations over the first year of adoptive placement: Narratives of maltreated children. Clinical Child Psychology and Psychiatry, 8, 351-367. doi: $10.1177 / 1359104503008003006$

Humfress, H., O'Connor, T. G., Slaughter, J., Target, M., \& Fonagy, P. (2002). General and relationship-specific models of social cognition: Explaining the overlap and discrepancies. Journal of Child Psychology and Psychiatry, 43(7), 873-883. doi:10.1111/1469-7610.0013_7

Hurry, A. (1998). Psychoanalysis and developmental therapy. London, UK: Karnac Books. Joseph, M. A., O'Connor, T. G., Briskman, J. A., Maughan, B., \& Scott, S. (2014). The formation of secure new attachments by children who were maltreated: an observational study of adolescents in foster care. Development and Psychopathology, 26(01), 67-80.

Lush, D., Boston, M., \& Grainger, E. (1991). Evaluation of psychoanalytic psychotherapy with children: Therapists' assessments and predictions. Psychoanalytic Psychotherapy, 5, 191-234. doi: 10.1080/02668739100700101

Midgley, N., Ansaldo, F., \& Target, M. (2014). The meaningful assessment of therapy outcomes: Incorporating a qualitative study into a randomized controlled trial evaluating the treatment of adolescent depression. Psychotherapy, 51, 128-137. doi: $10.1037 / \mathrm{a} 0034179$

Midgley, N., Ensink, K., Lindqvist, K., Malberg, N., \& Muller, N. (in press). Time-limited mentalization-based treatment for children $(M B T-C)$ : A treatment guide. Washington, DC: American Psychological Association. 
Midgley, N., Holmes, J., Parkinson, S., Stapley, E., Eatough, V., \& Target, M. (2016). 'Just like talking to someone about like shit in your life and stuff, and like they help you': Hopes and expectations for therapy among depressed adolescents. Psychotherapy Research, 26, 11-21. doi: 10.1080/10503307.2014.973922

Midgley, N., Isaacs, D., Weitkamp, K., \& Target, M. (2016). The experience of adolescents participating in a randomised clinical trial in the field of mental health: A qualitative study. Trials, 17, 364. doi: 10.1186/s13063-016-1474-2

Midgley, N., Parkinson, S., Holmes, J., Stapley, E., Eatough, V., \& Target, M. (2015). Beyond a diagnosis: The experience of depression among clinically-referred adolescents. Journal of Adolescence, 44, 269-279. doi:

10.1016/j.adolescence.2015.08.007

Midgley, N., Parkinson, S., Holmes, J., Stapley, E., Eatough, V., \& Target, M. (2017). "Did I bring it on myself?" An exploratory study of the beliefs that adolescents referred to mental health services have about the causes of their depression. European Child and Adolescent Psychiatry, 26, 25-34. doi 10.1007/s00787-016-0868-8

Midgley, N., \& Target, M. (2005). Recollections of being in child psychoanalysis: A qualitative study of a long-term follow-up project. Psychoanalytic Study of the Child, $60,157-177$.

Midgley, N., Target, M., \& Smith, J. (2006). The outcome of child psychoanalysis from the patient's point of view: A qualitative analysis of a long-term follow-up study. Psychology and Psychotherapy, 79, 257-269. doi: 10.1348/147608305X52694

Midgley, N., \& Vrouva, I. (Eds.). (2012). Minding the child: Mentalization-based interventions with children, young people and their families. London, UK: Routledge.

Moran, G., Fonagy, P., Kurtz, A., Bolton, A. \& Brook, C. (1991). A controlled study of psychoanalytic treatment of brittle diabetes. Journal of the American Academy of Child and Adolescent Psychiatry, 30, 926-935.

National Institute for Health and Care Excellence. (2015). Depression in children and young people: identification and management in primary, community and secondary care. Clinical Guideline 28. London, UK: British Psychological Society and Royal College of Psychiatrists.

National Institute for Health and Clinical Excellence. (2005). Depression in children and young people: Identification and management in primary, community and secondary care. Clinical Guideline 28. London, UK: British Psychological Society and Royal College of Psychiatrists. 
Oppenheim, D., Emde, R. N., \& Warren, S. (1997). Children's narrative representations of mothers: Their development and associations with child and mother adaptation. Child Development, 68, 127-138. doi: 10.1111/j.1467-8624.1997.tb01930.x

Parkinson, S., Eatough, V., Holmes, J., Stapley, E., \& Midgley, N. (2016). Framework analysis: A worked example of a study exploring young people's experiences of depression. Qualitative Research in Psychology, 13, 109-129. doi: 10.1111/j.14678624.1997.tb01930.x

Rosenfeld, S. K., \& Sprince, M. P. (1963). An attempt to formulate the meaning of the concept "borderline". The Psychoanalytic Study of the Child, 18, 603-635.

Roth, A., \& Fonagy, P. (1996). What works for whom? A critical review of psychotherapy research (1st ed.). New York, NY: Guilford Press.

Roth, A., \& Fonagy, P. (2005). What works for whom? A critical review of psychotherapy research (2nd ed.). New York, NY: Guilford Press.

Sandler, J. (1962). The Hampstead Index as an instrument of psycho-analytic research. International Journal of Psycho-Analysis, 43, 287-291.

Schachter, A. \& Target, M. (2009). The adult outcome of child psychoanalysis: The Anna Freud Centre long-term follow-up study. In N. Midgley, J. Anderson, E. Grainger, T. Nesic-Vuckovic, \& C. Urwin (Eds.), Child psychotherapy and research: New approaches, emerging findings (pp. 144-155). London, UK: Routledge.

Shaffer, D., Gould, M. S., Brasie, J., Ambrosini, P., Fisher, P., Bird, H., \& Aluwahlia, S. (1983). A children's global assessment scale (CGAS). Archives of General Psychiatry, 40, 12281231.

Shmueli-Goetz, Y., Target, M., Fonagy, P., \& Datta, A. (2008). The Child Attachment Interview: A psychometric study of reliability and discriminant validity. Developmental Psychology, 44, 939-956. doi: 10.1037/0012-1649.44.4.939

Stapley, E., Midgley, N., \& Target, M. (2016). The experience of being the parent of an adolescent with a diagnosis of depression. Journal of Child and Family Studies, 25, 618-630. doi: 10.1007/s10826-015-0237-0

Stapley, E., Midgley, N. \& Target, M. (2017). The journey through and beyond mental health services in the UK: A typology of parents' ways of managing the crisis of their teenage child's depression. Journal of Clinical Psychology. Advance online publication. doi: 10.1002/jclp.22446 
Steele, H., Steele, M., \& Croft, C. (2008). Early attachment predicts emotion recognition at 6 and 11 years old. Attachment \& Human Development, 10, 379-393. doi: $10.1080 / 14616730802461409$

Target, M., \& Fonagy, P. (1994a). Efficacy of child psychoanalysis for children with emotional disorders. Journal of the American Academy of Child and Adolescent Psychiatry, 33, 361-371. doi: 10.1097/00004583-199403000-00010

Target, M., \& Fonagy, P. (1994b). The efficacy of psychoanalysis for children: Prediction of outcome in a developmental context. Journal of the American Academy of Child and Adolescent Psychiatry, 33, 1134-1144. doi: 10.1097/00004583-199410000-00009

Target, M., \& Fonagy, P. (1996). The psychological treatment of child and adolescent psychiatric disorders. In A. Roth, \& P. Fonagy (Eds.), What works for whom? A critical review of psychotherapy research (pp. 263-320). New York, NY: Guilford Press.

Target, M., \& Fonagy, P. (2003). Attachment theory and long-term psychoanalytic outcome: Are insecure attachment narratives less accurate? In M. Leuzinger-Bohleber, A. U. Dreher, \& J. Canestri (Eds.), Pluralism and unity? Methods of research in psychoanalysis (pp. 149-167). London, UK: International Psychoanalytical Association.

Target, M., Shmueli-Goetz, Y., \& Fonagy, P. (2003). Attachment representations in schoolage children: The development of the Child Attachment Interview (CAI). Journal of Child Psychotherapy, 29, 171-186.

Target, M., Fonagy, P., Schneider, T., Ensink, K., \& Janes, K. (2000). Raters' Manual for the Hampstead Child Adaptation Measure (HCAM). London, UK: University College London and The Anna Freud Centre.

Trowell, J., Kolvin, I., Weeramanthri, T., Sadowski, H., Berelowitz, M., Glasser, D., \& Leitch, I. (2002). Psychotherapy for sexually abused girls: Psychopathological outcome findings and patterns of change. British Journal of Psychiatry, 180, 234 247. doi: 10.1192/bjp.180.3.234

Trowell, J., Joffe, I., Campbell, J., Clemente, C., Almqvist, F., Soininen, M., . . Tsiantis, J. (2007). Childhood depression: A place for psychotherapy. An outcome study comparing individual psychodynamic psychotherapy and family therapy. European Child and Adolescent Psychiatry, 16, 157-167. doi: 10.1007/s00787-006-0584-X

Westen, D., Muderrisoglu, S., Fowler, C., Shedler, J. \& Koren, D. (1997). Affect regulation and affective experience: Individual differences, group differences, and measurement 
using a Q-sort procedure. Journal of Consulting and Clinical Psychology, 65, 429439. doi: 10.1037/0022-006X.65.3.429 